\title{
Vitamin D Status and Cognitive Performance of Post Stroke Patients
}

\author{
Rizaldy Pinzon ${ }^{1,2}$, Vincent Ongko Wijaya ${ }^{1,2}$, Dessy Paramitha ${ }^{1,2}$ \\ ${ }^{1}$ Faculty of Medicine, Duta Wacana Christian University, Yogyakarta, Indonesia \\ ${ }^{2}$ Bethesda Hospital, Yogyakarta, Indonesia
}

Background: The prevalence of post-stroke cognitive impairment (PSCl) ranges from $20-80 \%$. Some studies found that vitamin $D$ deficiency was common in stroke patients, yet the relationship with cognitive performance remains unclear. The study aimed to investigate the relationship between levels of vitamin $D$ and cognitive performance in post-stroke patients. Materials and Methods: This was a cross-sectional study with 20 post-ischemic stroke patients. Vitamin D levels were measured using enzyme-linked fluorescent assay (ELFA). The cognitive performance was assessed by computerized minimental state examination (MMSE) and clock drawing test (CDT). The relationship between vitamin $D$ levels and cognitive tests were performed using paired T-test.

Results: Vitamin D insufficiency $(<30 \mathrm{ng} / \mathrm{mL}$ ) was experienced by all of the study subjects $(100 \%)$, with the mean $\pm S D$ of vitamin D level was $13.75 \pm 4.06 \mathrm{ng} / \mathrm{mL}$. More than $70 \%$ subjects had cognitive impairment. Based on MMSE, patients with cognitive impairment had lower vitamin D levels, compared with those patients with normal cognition $(13 \pm 4.38 \mathrm{vs}$. $16 \pm 2.44$ $\mathrm{ng} / \mathrm{mL}, p<0.001)$. In CDT examination, patients with cognitive impairment had slightly higher vitamin $D$ levels, compared with those patients with normal cognition $(13.93 \pm 4.25$ vs. $13.33 \pm 3.93 \mathrm{ng} / \mathrm{mL}, p<0.001)$.

Conclusion: The insufficiency of vitamin D on post-ischemic stroke patients appears to generate a bigger chance of PSCI occurrence. Physicians should be aware of vitamin D status of post-stroke patients, especially in the older population.

Keywords: vitamin D levels, post-stroke cognitive impairment, risk factors

\section{Introduction}

Vitamin D is a fat-soluble vitamin that mainly responsible for calcium and phosphorus metabolism and bone mineralization.(1) Vitamin D deficiency is a very common problem and arises from multiple causes, including inadequate dietary intake and inadequate exposure to sunlight or certain medical condition. The epidemiological data on the previous study has report one billion cases of worldwide vitamin $\mathrm{D}$ deficiency, with the highest prevalence in the elderly, obese patients, nursing home residence, and hospitalized patients. The previous study also reports of

Date of submission: June 27, 2020

Last Revised: September 27, 2020

Accepted for publication: October 2, 2020

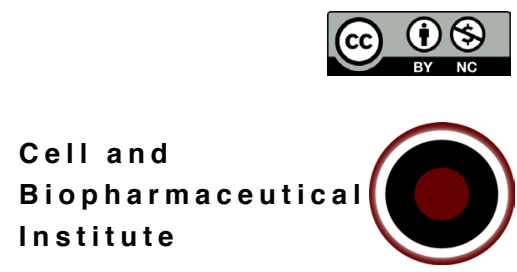

Corresponding Author:

Dessy Paramitha

Faculty of Medicine, Duta Wacana Christian University

Jl. Dr. Wahidin Sudirahusada 5-25

Yogyakarta, 55224, Indonesia

e-mail: dessyparamitha02@gmail.com 
vitamin D insufficiency prevalence that reaches as much as $50 \%$ of the population.(2)

Stroke is the second most common cause of death globally and leads to $9 \%$ of all deaths. Hypertension, hyperlipidemia, smoking, diabetes mellitus, obesity, and atrial fibrillation are among the modifiable risk factors for ischemic stroke. In 2018, stroke was the leading cause of in-hospital mortality based on the Indonesian Basic Health Survey.(3) Recent studies showed that vitamin D deficiency was found in stroke patients. Vitamin D deficiency was associated with hypertension, hyperlipidemia, and diabetes (all the vascular risk factors for stroke).(3-5).

Previous studies either in animals and humans suggest that impaired brain physiological function might happen because of vitamin $\mathrm{D}$ deficiency. There is also proof that vitamin $\mathrm{D}$ had a protective ability against biological processes associated with Alzheimer's disease and cognition. $(6,7)$ There are limited data from the Indonesian series on the correlation between vitamin $\mathrm{D}$ with brain function and cognition, especially with the post-stroke cognitive function. Thus, this study aims to investigate the correlation between Vitamin D levels and cognitive performances of postischemic stroke patients in Bethesda hospital Yogyakarta Indonesia.

\section{Materials and methods}

This retrospective study was approved by the Bethesda Hospital Ethics Committee with ethical approval letter No. KEP/RS Bethesda/376. Oral informed consent was obtained from all study participants followed by each of them signing a letter of approval to be the respondent in this study.

\section{Study Population}

We used consecutive sampling, where subjects were recruited within a period of 1 month. The inclusion criteria were patients older than 18-year-old and diagnosed with ischemic stroke. The diagnosis of ischemic stroke was made by a neurologist based on neurological and radiological examination.

\section{Data Collection}

Patients' data were obtained from the electronic medical record and information system of Head Computed Tomography (CT) scan of hospital stroke registry. The data of cognitive performance was measured by standard computerized mini-mental status examination (MMSE) and clock drawing test (CDT) test in the memory clinic at Bethesda Hospital, Yogyakarta. MMSE score of $<24$ out of 30 and/or CDT score $\leq 2$ out of 4 were indicated as cognitive and memory impairment. MMSE and CDT were proved as valid tools to evaluate subjects with mild cognitive impairment (MCI) while also capable of differentiated patients with various types of dementia. The affordable and easy to used nature of both test are another advantage that makes standard computerized MMSE and CDT test were considered to be used in this study.(8) CT scan examination on study respondents was carried out on the same day the patient was admitted to the hospital. MMSE and CDT examinations in patients were carried out within the same week to $<14$ days from the day the patient was hospitalized The vitamin D level was measured with a standardized laboratory method using enzyme-linked fluorescent assay (ELFA). The measurement was carried out with serum or plasma that will be examined on VIDAS ${ }^{\circledR} 25 \mathrm{OH}$ Vitamin D (bioMérieux, Marcy l'Etoile, France). In this study, we measured the 25-hydroxyvitamin D [25(OH)D] which was the inactive form of vitamin $\mathrm{D}$ and the major form found in the blood to assess vitamin D status in participants. Vitamin D deficiency had been defined as levels of $25(\mathrm{OH})$ D less than $20 \mathrm{ng} / \mathrm{mL}$, while levels below $30 \mathrm{ng} / \mathrm{mL}$ indicate vitamin D insufficiency.(9)

\section{Data Analysis}

Percentages and count were used for represented the categorical variable while mean and standard deviation (SD) were used for normally distributed data on baseline data. Due to the small number of respondents, the normality test was done using the Shapiro-Wilk test. Correlations between the vitamin D level and cognitive performance were measured by paired T-test. Statistical analysis was performed using the SPSS 26.0 software (IBM SPSS Statistics, New York, USA). The level of significance was set at $p<0.05$.

\section{Results}

A total of 20 subjects with a history of ischemic stroke were included in the study. Their clinical characteristics were shown in Table 1. Their mean \pm SD age was $67.7 \pm 9.4$ years, and 11 were male patients (55\%). All of these patients had at least 1 of the following underlying disorders: hypertension $(20 \%)$, diabetes $(30.0 \%)$, and dyslipidemia $(75 \%)$. Five patients $(20 \%)$ also had a history of cigarette smoking in the past. Based on the head CT scan imaging, most of 
Table 1. Clinical characteristics of post-stroke patients.

\begin{tabular}{|c|c|}
\hline Characteristics & $\begin{array}{l}\text { Value } \\
(n=20)\end{array}$ \\
\hline Age (year), mean \pm SD & $67.7 \pm 9.4$ \\
\hline \multicolumn{2}{|l|}{ Sex, $n(\%)$} \\
\hline Male & $11(55)$ \\
\hline Female & $9(45)$ \\
\hline \multicolumn{2}{|l|}{ Comorbidities, n (\%) } \\
\hline Hypertension & $4(20)$ \\
\hline Diabetes & $6(30)$ \\
\hline Dyslipidemia & $15(75)$ \\
\hline \multicolumn{2}{|l|}{ History of Smoking, $\mathrm{n}(\%)$} \\
\hline Yes & $5(25)$ \\
\hline No & $15(75)$ \\
\hline \multicolumn{2}{|l|}{ Infarct Location, n (\%) } \\
\hline Not visible & $7(35)$ \\
\hline Frontal lobe & $0(0)$ \\
\hline Parietal lobe & $4(20)$ \\
\hline Temporal lobe & $1(5)$ \\
\hline Multiple locations & $8(40)$ \\
\hline \multicolumn{2}{|l|}{ Medication, n (\%) } \\
\hline Anti-platelet & $20(100)$ \\
\hline Statin & $14(70)$ \\
\hline Citicoline & $4(20)$ \\
\hline Vitamin D $(\mathrm{ng} / \mathrm{mL})$, mean $+\mathrm{SD}$ & $13.75 \pm 4.06$ \\
\hline \multicolumn{2}{|l|}{ Vitamin D Levels, n (\%) } \\
\hline Sufficient $(\geq 30 \mathrm{ng} / \mathrm{mL})$ & $0(0)$ \\
\hline Insufficiency $(<30 \mathrm{ng} / \mathrm{mL})$ & $20(100)$ \\
\hline MMSE score, mean + SD & $19.15 \pm 4.26$ \\
\hline \multicolumn{2}{|l|}{ MMSE Score, n (\%) } \\
\hline$\geq 24$ (normal) & $5(25)$ \\
\hline$<24$ (cognitive impairment) & $15(75)$ \\
\hline CDT Score, mean + SD & $1.35 \pm 1.42$ \\
\hline \multicolumn{2}{|l|}{ CDT Score, n (\%) } \\
\hline$>2$ (normal) & $6(30)$ \\
\hline$\leq 2$ (cognitive impairment) & $14(70)$ \\
\hline
\end{tabular}

the patients had multiple locations of infarct (40\%). In 7 patients, the location of the stroke was not visible through the scan.

All the patients received antiplatelet such as aspirin or clopidogrel for their post-stroke treatment. Fourteen patients (70\%) received statins, and 4 patients $(20 \%)$ received citicoline. All of the patients in this study had insufficiency $(<30 \mathrm{ng} / \mathrm{mL})$ levels of vitamin $\mathrm{D}$, with the mean level was $13.75 \pm 4.06 \mathrm{ng} / \mathrm{mL}$. Their cognitive performance was measured using 2 scales including MMSE and CDT. From the MMSE examination, most of the patients had cognitive impairment (75\%). Similarly, the CDT examination showed cognitive impairment $(70 \%)$ was common in our patients.

Table 2 showed the comparison of vitamin D levels in cognitive impairment and normal patients based on MMSE total score. Patients with cognitive impairment had lower vitamin D levels, compared with those patients with normal cognition $(13 \pm 4.38 \mathrm{ng} / \mathrm{mL}$ vs. $16 \pm 2.44 \mathrm{ng} / \mathrm{mL} ; \mathrm{p}<0.001)$. The comparison of vitamin D levels in cognitive impairment and normal patients based on CDT total score was also shown in Table 2. Patients with cognitive impairment had slightly increased vitamin D levels, compared with those patients with normal cognition $(13.93 \pm 4.25 \mathrm{ng} / \mathrm{mL}$ vs. $13.33 \pm 3.93$ $\mathrm{ng} / \mathrm{mL} ; p<0.001)$.

\section{Discussion}

Ischemic stroke is a major cause of death and long-term disability globally. The result showed that all of the study subjects have low vitamin D levels $(<30 \mathrm{ng} / \mathrm{mL})$, thus make them diagnosed by vitamin D insufficiency. Some studies showed that there is a relation between vitamin D deficiency with the risk and prognosis of ischemic stroke patients. $(10,11)$ The mechanism was explained by recent findings on vitamin $\mathrm{D}$ roles in influencing atherosclerosis forming by regulating inflammatory activity within vascular walls and regulating renin production, thus attenuating hypertension. $(12,13)$

Cognitive measurements using MMSE and CDT on all subjects in this study showed most of the post-ischemic stroke patients with vitamin D insufficiency had cognitive impairment. This might imply that post-ischemic stroke patients with vitamin D insufficiency tend to undergo PSCI. This result was consistent with a previous study that showed a 2,124-fold increase in the risk of PSCI on patients with vitamin D deficiency.(14)

There has been a detailed explanation of how PSCI might occur on post-stroke patients, but there is no detailed explanation yet of how vitamin D can affect cognitive function. A recent trial study in Japan, showed low vitamin D levels are related to poor prognosis after stroke. Still, whether vitamin D supplementation of post-stroke patients can improve these outcomes remains unclear.(15)

Another study found that vitamin D showed an ability to initiate neurogenesis and regulated the synthesis of several neotropics factors that influence neuronal growth, 
Table 2. Comparison of vitamin D levels and cognitive performance on MMSE and CDT.

\begin{tabular}{|c|c|c|c|c|}
\hline \multirow[t]{2}{*}{ Examination Type } & \multicolumn{2}{|c|}{$\begin{array}{c}\text { Vitamin D Levels }(\mathrm{ng} / \mathrm{mL}) \\
\text { mean } \pm \text { SD }\end{array}$} & \multirow[t]{2}{*}{$95 \% \mathrm{CI}$} & \multirow[t]{2}{*}{$p$-value } \\
\hline & Cognitive Impairment Group & Normal Group & & \\
\hline MMSE Score & $13.00 \pm 4.38$ & $16.00 \pm 2.44$ & $10.02-13.98$ & $<0.001$ \\
\hline CDT Score & $13.93 \pm 4.25$ & $13.33 \pm 3.93$ & $10.33-14.47$ & $<0.001$ \\
\hline
\end{tabular}

differentiation, and maturation.(16) That was considered as something that might be related to the development of PSCI in a previous study.(14)

There is a difference in the number of respondents who experienced PSCI which the MMSE examination finds more patients with PSCI $(n=16)$ than the CDT examination $(n=15)$. This difference result could happen because of the lack of sensitivity of the CDT compared with MMSE, thus make CDT possibly detected fewer patients with PSCI then MMSE.(17)

There is also been found a slightly higher vitamin D concentration in PSCI patients compared with the normal patients in the CDT result (13.93 ng/mL vs. $13.33 \mathrm{ng} / \mathrm{mL})$. This result was contradictory to our hypothesis on how a lower vitamin D concentration brought a greater risk of PSCI. We believed that it is important to take into account how the vitamin D concentration on both groups was already considered as vitamin $\mathrm{D}$ insufficient and the vitamin $\mathrm{D}$ concentration was just being slightly different $(0.6 \mathrm{ng} /$ $\mathrm{mL})$.

This study managed to present information about Vitamin D levels and cognitive performances of postischemic stroke patients. However, it has several limitations, such as an absence of post-ischemic stroke patients with normal vitamin D levels included as a comparison and the limited number of stroke subjects due to the short timeframe of this study. This study also did not take into account the other risk factors of PSCI that have already been diagnosed in patients. We encourage further study to do a comparison test between a PSCI diagnosed group and a normal cognitive group. We also suggest doing the test of homogeneity on each group to reach a more pragmatic result.

\section{Conclusion}

The insufficiency of vitamin D in post-ischemic stroke patients appeared to generate a bigger chance of PSCI occurrence, based on the high rate of PSCI cases in the result. The CDT lack of sensitivity might become a reason for the difference in the MMSE and CDT result in this study. There is no detailed information on the mechanism of vitamin D on cognitive function, but there are new findings on vitamin $\mathrm{D}$ roles in brain health and function that might relate to PSCI cases in post-stroke patients.

\section{Acknowledgments}

Authors have no conflict of interest to disclose, including personal relationships, financial or otherwise. This research was personally funded by the authors.

\section{References}

1. Fidan F, Alkan BM, Tosun A. Pandemic era: vitamin D deficiency and insufficiency. Turkish Journal of Osteoporosis. 2014; 20(2): 71-4.

2. Sizar O, Khare S, Goyal A, Bansal P, Givler A. Vitamin D deficiency. In: StatPearls [Internet]. Treasure Island (FL): StatPearls Publishing; 2020

3. Kementerian Kesehatan. Indonesian Based Health Survey/Riset Kesehatan Dasar Indonesia 2018. Jakarta: Kementerian Kesehatan; 2018.

4. Narasimhan S. Role of vitamin D in the outcome of ischemic stroke: a randomized controlled trial. J Clin Diagn Res. 2017; 11(2): CC06$\mathrm{CC} 10$.

5. Wei ZN, Kuang JG. Vitamin D deficiency in relation to the poor functional outcomes in nondiabetic patients with ischemic stroke. Biosci Rep. 2018; 38(2): BSR20171509. doi: 10.1042/ BSR20171509.

6. Turetsky A, Goddeau RP Jr, Henninger N. Low serum vitamin D is independently associated with larger lesion volumes after ischemic stroke. J Stroke Cerebrovasc Dis. 2015; 24(7): 1555-63. doi: 10.1016/j.jstrokecerebrovasdis.2015.03.051.

7. Anastasiou CA, Yannakoulia M, Scarmeas N. Vitamin D, and cognition: an update of the current evidence. JAD. 2014; 42(3): S71-80.

8. Sallam K, Amr M. The use of the mini-mental state examination and the clock-drawing test for dementia in a tertiary hospital. J Clin Diagn Res. 2013;7(3): 484-488.

9. Nair R, Maseeh A. Vitamin D: The "sunshine" vitamin. J Pharmacol Pharmacother. 2012; 3(2): 118-26.

10. Berghout BP, Fani L, Heshmatollah A, Koudstaal PJ, Kram MA, Zillikens MC, et al. Vitamin D status and risk of stroke: The Rotterdam Study. Stroke. 2019; 50(9): 2293-8.

11. Moretti R, Morelli ME, Caruso P. Vitamin D in neurological diseases: a rationale for a pathogenic impact. Int J Mol Sci. 2018; 19(8): 2245. doi: 10.3390/ijms 19082245 . 
12. Chen Y, Liu W, Sun T, Huang Y, Wang Y, Deb DK, et al. 1,25-dihydroxy vitamin D promotes negative feedback regulation of TLR signaling via targeting microRNA-155-SOCS1 in macrophages. J Immunol. 2013; 190(7): 3687-95.

13. Takeda M, Yamashita T, Sasaki N, Nakajima K, Kita T, Shinohara M, et al. Oral administration of an active form of vitamin D3 (calcitriol) decreases atherosclerosis in mice by inducing regulatory $\mathrm{T}$ cells and immature dendritic cells with tolerogenic functions. Arterioscler Thromb Vasc Biol. 2010; 30(12): 2495-503.

14. Chen H, Liu Y, Huang G, Zhu J, Feng W, He J. Association between vitamin $\mathrm{D}$ status and cognitive impairment in acute ischemic stroke patients: a prospective cohort study. Clin Interv Aging. 2018; 13: 2503-9.

15. Momosaki R, Abo M, Urashima M. Vitamin D supplementation and post-stroke rehabilitation: a randomized, double-blind, placebocontrolled trial. Nutrients. 2019; 11(6): 1295. doi: 10.3390/ nu11061295.

16. Annweiler C. Vitamin D in dementia prevention. Ann NY Acad Sci. 2016; 1367(1): 57-63.

17. Palsetia D, Rao GP, Tiwari SC, Lodha P, De Sousa A. The clock drawing test versus mini-mental status examination as a screening tool for dementia: a clinical comparison. Indian J Psychol.Med. 2018; 40(1): 1-10. 